\title{
A CLÁUSULA REBUS SIC STANTIBUS À LUZ DA JUSTIÇA COMUTATIVA ARISTOTÉLICA
}

\author{
Márcio Eduardo Senra Nogueira Pedrosa Morais ${ }^{4}$ \\ Moisés Carvalho de Melo ${ }^{5}$
}

Recebido em: 21/10/2019

Aprovado em: 06/02/2020

\begin{abstract}
RESUMO
A cláusula rebus sic stantibus, positivada no ordenamento jurídico brasileiro, tem estrita relação principiológica com a justiça comutativa, elaborada por Aristóteles (384 a.C.-322 a.C.), especialmente no que tange à teleologia. A teoria da imprevisão objetiva promover justiça nas relações contratuais quando alteram-se as circunstâncias, em vista do equilíbrio de benefícios e perdas das partes. O estudo, de método hipotético-dedutivo, amparado em expositores da doutrina jusfilosófica aristotélica e da história e aplicação da cláusula rebus sic stantibus, tem como escopo analisar os assuntos, em seus pressupostos filosóficos e seu âmbito histórico, em vista de encontrar convergências e influências. Conclui-se pela manifesta relação dos elementos basilares dos institutos, que tem a mesma finalidade, embora não seja possível afirmar-se cabalmente o liame histórico de influência da doutrina aristotélica no surgimento da cláusula.
\end{abstract}

Palavras chave: Justiça comutativa. Justiça distributiva. Cláusula rebus sic stantibus. Brasil.

\section{INTRODUÇÃO}

A filosofia grega é uma das bases estruturantes da civilização ocidental. É difícil encontrar institutos e elementos jurídicos, políticos e culturais na sociedade moderna que não tenham, de alguma forma, pelo menos, sido influenciados por este importante movimento histórico. Os gregos influenciaram os romanos, ainda que por estes dominados politicamente. Posteriormente, tiveram

\footnotetext{
${ }^{4}$ Doutor em Teoria do Direito pela Pontifícia Universidade Católica de Minas Gerais. Professor da Universidade de Itaúna/MG. Professor da Faculdade de Pará de Minas.

${ }^{5}$ Graduado em Direito pela Universidade de Itaúna. Advogado
} 
importantíssima contribuição na filosofia e no direito, especialmente na escolástica. Dentre os gênios gregos, destaca-se o de Aristóteles (384 a.C.-322 a.C.).

Com Aristóteles tem-se uma das primeiras concepções de justiça desenvolvidas no ocidente, por intermédio da obra Ética a Nicômaco, manual dedicado ao filho. O Estagirita apresenta o justo sinteticamente em duas modalidades: distributiva e comutativa.

A justiça distributiva diz respeito à distribuição de honras, bens e cargos, e tem como critério o mérito do indivíduo receptor. Geralmente aplica-se a relações multilaterais. Impõe um postulado de proporcionalidade, não de igualdade. Distribui-se de acordo com o que é devido.

Por sua vez, a justiça comutativa, também designada de justiça corretiva, visa à igualdade e aplica-se especialmente às relações sinalagmáticas entre particulares, como os contratos. Seu postulado de igualdade tem como fim impedir que uma das partes da relação se beneficie mais que a outra, o que configuraria desequilíbrio.

É sobre esta última modalidade de justiça que trata especificamente este trabalho. No ideal de igualdade que desta advém, pode-se encontrar os fundamentos deônticos de uma série de institutos caros aos ordenamentos jurídicos dos países ocidentais, tais como o enriquecimento ilícito e sua correlata cláusula rebus sic stantibus.

Com efeito, a rebus sic stantibus - expressão que provavelmente surgiu no medievo e que significa enquanto as coisas estão assim - constitui verdadeira afronta ao tradicional pacta sunt servanda. Este último preceito, que em suma determina que o que foi acordado deve ser cumprido, sem exceções, fere evidentemente a justiça comutativa, especialmente nos casos em que há mudança das circunstâncias sobre as quais se baseou o acordo. Aqui se justifica a necessidade da rebus sic stantibus, como cláusula implícita nas relações contratuais: corrigir o desequilíbrio entre as partes, causado pelas novas circunstâncias, com o escopo de fazer justiça comutativa.

Diante do exposto, parece haver estrita relação principiológica entre a doutrina de Aristóteles e a cláusula positivada (inclusive) no ordenamento jurídico brasileiro, o que constitui o problema basilar sobre o qual se detém o trabalho. A hipótese motivadora é que a doutrina aristotélica influenciou direta ou indiretamente, ao menos como base filosófica das discussões dos medievais, na gênese da rebus sic stantibus.

Destarte, o presente trabalho tem como objetivo analisar a importante doutrina da justiça comutativa de Aristóteles, com suas argumentações e justificativas, fazendo comparação analítica desta com o instituto da cláusula rebus sic stantibus, ou teoria da imprevisão, como denominada 
pela doutrina francesa, em vista de se encontrar postulados comuns e provável influência no surgimento histórico da última cláusula, especialmente no tocante às suas bases filosóficas.

Não se objetiva afirmar cabalmente que a rebus sic stantibus teve sua origem em Aristóteles, mas sim analisar elementos similares entre a cláusula e a doutrina do Estagirita. Como será visto, a discussão sobre sua gênese é demasiadamente complexa, com infindáveis discussões. A hipótese é a de que a teoria da imprevisão e a doutrina da justiça comutativa têm a mesma finalidade e o mesmo princípio filosófico gerador, o que aponta, em tese, para forte influência histórica.

O trabalho se justifica em razão da aplicabilidade da cláusula no ordenamento jurídico pátrio. Eis que um instituto tanto mais é compreendido e, assim, bem aplicado, quanto se conhece sua história, seus pressupostos filosóficos e especialmente de suas finalidades. Assim, o pensamento aristotélico pode trazer outros elementos para a estruturação do conceito da cláusula rebus sic stantibus, sendo, desse modo, útil à Ciência do Direito, que está em constante modificação e aperfeiçoamento.

Estruturalmente, o estudo está divido em três seções: na primeira, apresenta-se a teoria de justiça em Aristóteles, com suas duas vertentes, comutativa e distributiva, distinguindo-as e descrevendo suas bases. Na segunda seção, expõe-se a história da cláusula rebus sic stantibus, seu significado a aplicação, bem como sua previsão no ordenamento jurídico pátrio. Finalmente, encerrada a parte expositiva, na terceira seção passa-se ao que formalmente visa o trabalho, parte na qual faz-se a análise comparativa entre os institutos estudados.

Quanto à abordagem do problema, a pesquisa, de natureza teórica, é de tipo qualitativa, pois tem em vista o aprofundamento da compreensão dos institutos postos em comparação.

O referencial teórico ampara-se em expositores da história e da filosofia do direito, como Michel Villey (2005), Giorgio Del Vecchio (2006), bem como da doutrina civilista brasileira. Por sua vez, a apresentação da história da cláusula rebus sic stantibus tem como base especialmente a obra de Anísio José de Oliveira (1968). Ademais, sustenta-se no discípulo medieval de Aristóteles, Santo Tomás de Aquino.

Diante do exposto, passa-se na próxima seção ao estudo da estruturação do conceito aristotélico de justiça. 


\section{ARISTÓTELES E A SUA ESTRUTURAÇÃO TEÓRICA ACERCA DO CONCEITO DE JUSTIÇA}

O gênio do Estagirita ${ }^{6}$ alcançou praticamente todas as ciências, deixando um importante legado em diversos ramos do conhecimento, tais como a ética, a lógica (com seu órganon), a metafísica, a política, a física e o direito, o que especialmente interessa a esta pesquisa. Propugnou, inclusive, a natureza política e social do homem, afirmando ser o homem um animal político (zoon politikon).

Em meio a seus ensinamentos sobre o direito e a justiça, estabelecendo a igualdade como o escopo desta última, Aristóteles legou importante classificação entre a justiça distributiva e a justiça comutativa, que posteriormente seria objeto de importantes discussões e tratados por quase todos os filósofos do Direito. Sobre a filosofia aristotélica, ressalta Leo Strauss (2013) que o primeiro modelo de justiça decorre do exercício da distribuição de honrarias, riqueza, não sendo essa justiça baseada na igualdade aritmética, mas sim numa igualdade de proporções entre pessoas e bens. Deste modo, uma distribuição justa envolve a distribuição de partes iguais para pessoas iguais e de partes desiguais para pessoas desiguais.

A justiça distributiva é controversa na medida em que a discriminação entre as pessoas se baseia no mérito e numa questão política. Por sua vez, o segundo tipo de justiça envolve transações, às quais Aristóteles denomina corretiva. Neste sentido, a justiça abstrai os indivíduos e "aplica uma igualdade aritmética simples aos indivíduos e bens em questão; estende-se não apenas as transações voluntárias, tais como contratos, mas a atos involuntários ou criminosos, como roubo ou assassinato". (STRAUSS, 2013, p. 118).

Tal classificação, que será estudada nas próximas subseções, formulou Aristóteles especificamente na quinta parte (Livro V) de Ética da Nicômaco, parte da obra que trata da estruturação do conceito de justiça, haja vista que o livro aborda outros elementos comuns à ciência jurídica.

\footnotetext{
${ }^{6}$ Aristóteles nasceu em 384 a.C., em Estagira, colônia jônica, na Macedônia, Grécia. Filho de Nicômaco, médico do rei Amintas III, recebeu desde cedo boa formação sobre as ciências naturais. Ainda jovem, dirigiu-se a Atenas, onde por mais de vinte anos foi aluno de Platão (428 $\square 427$ a.C.-348 $\square 347$ a.C.), em sua academia. Após a morte de seu mestre, recebeu o convite de Felipe II para ser o preceptor de Alexandre, que seria conhecido futuramente sob o epíteto "O Grande". No mesmo ano que Alexandre realizou sua expedição ao Oriente, Aristóteles retornou a Atenas, passando a ensinar próximo ao templo de Apolo Lício. Por esta razão, sua escola foi denominada Liceu. Em seu ensinamento, contrariou seu antigo mestre, defendendo a existência das ideias (ou formas) nas próprias coisas, o que foi denominado realismo (ou realismo moderado). Por sua vez, Platão propugnava a existência à parte das ideias, separadas das coisas, vide sua famosa alegoria da caverna.
} 
Outrossim, o mais importante discípulo medieval de Aristóteles, Santo Tomás de Aquino, apresentou a mesma divisão, em sua Suma Teológica:

\begin{abstract}
A justiça particular se ordena a uma pessoa privada, que está para a comunidade como a parte, para o todo. Ora, as partes são susceptíveis de dupla relação. Uma, entre si, a que se assemelham as relações das pessoas particulares entre si. E, esta relação é dirigida pela justiça comutativa, que regula os atos entre duas pessoas particulares. - Outra é a relação entre o todo e as partes, à qual é comparável a relação entre o comum e o particular. E essas relações as dirige a justiça distributiva, que distribui os bens comuns proporcionalmente. Por onde, duas são as espécies de justiça: a distributiva e a comutativa. (AQUINO, 2016, V. 3, p. 394).
\end{abstract}

Em resumo, de acordo com o esquema aristotélico, a justiça particular se subdivide em justiça comutativa e justiça distributiva.

\title{
2.1 A justiça distributiva no pensamento aristótelico
}

Conforme ressaltado alhures, é sabido que a expressão "justiça distributiva" foi lançada por Aristóteles, no Livro V de Ética a Nicômaco, quando, ao lado do justo total, Aristóteles discorreu sobre o justo particular, sendo esse dividido em justiça corretiva, o que posteriormente chamar-seá de justiça comutativa e justiça distributiva. Pelo fato de o injusto ser o desigual, existe um meio termo do desigual, e este é o igual. Do mesmo modo, sendo o igual um meio termo, o justo também será um meio termo, necessitando o justo de duas condições. Nestes moldes, necessariamente, o justo é um meio termo.

Destarte, quando aqueles que são iguais não recebem partes iguais ou quando os iguais recebem partes desiguais, acusações são suscitadas. Assim, para Aristóteles, a justiça distributiva requer que honra, posições de autoridade política, direitos políticos, sejam distribuídos de acordo com os méritos de cada um, residindo o mérito de acordo com a estratificação social, "mas não todos coincidem em relação ao mérito mesmo, os democratas os põem na liberdade, os oligarcas na riqueza ou na nobreza e os aristocratas na virtude". (ARISTÓTELES, 1988, p. 243, tradução nossa). ${ }^{7}$

\footnotetext{
${ }^{7}$ Pero no todos coinciden en cuanto al mérito mismo, sino que los demócratas lo ponen en la libertad, los oligárquicos en la riqueza o nobleza, y los aristócratas en la virtud.
} 
Assim, conclui-se que o justo é uma espécie de proporção, requerendo quatro termos. A é a B, como B é a C. O termo B se menciona duas vezes, os termos A e B uma vez, totalizando assim os quatro termos da proporção. ${ }^{8}$

Na justiça comutativa objetiva-se a compensação de um dano independente de mérito, como a injúria, por exemplo, a vítima da injúria terá, através da justiça comutativa, o direito de ser compensada pelos danos sofridos. Compensa-se até pessoas más pelos danos sofridos, tendo como base apenas o grau do dano sofrido. A justiça distributiva, de outro lado, visa a garantir uma compensação, todavia, ancorada em um mérito. Nestes termos, para a justiça distributiva, a compensação, aqui entendida como distribuição de bens, dar-se-á de acordo com aquilo que elas merecem.

$\mathrm{O}$ aspecto que Aristóteles mais se preocupa na justiça distributiva é de como se dará a distribuição de direitos políticos (Livro III, A Política), a participação política (a capacidade para votar ou exercer cargos políticos). A distribuição justa toma o valor do que um homem contribui para um objetivo comum e o valor do benefício que deriva do mesmo. Para os democratas todos os cidadãos nascidos livres são iguais parceiros na comunidade, enquanto que os oligarcas afirmam que os ricos contribuem mais. Deste modo, a distribuição de vantagens políticas deve ser mais vantajosa aos homens livres numa democracia e aos mais ricos numa oligarquia. (HUTCHINSON, 1995).

Santo Tomás de Aquino adota a concepção de justiça distributiva de Aristóteles, dividindo a justiça em duas espécies: comutativa e distributiva, com clara inspiração aristotélica. A justiça particular, para Aquino (1990), está ordenada a uma pessoa privada, que, em relação com a comunidade, é como a parte em relação ao todo. A justiça distributiva, por sua vez, cuida da distribuição proporcional dos bens comuns.

Ademais, além de aceitar e compreender a justiça tendo como espécies a distributiva e a comutativa, Aquino (1990), mais uma vez mantendo o posicionamento aristotélico salienta que a justiça distributiva tem o objetivo de distribuir bens, novamente a distribuição é proporcional ao mérito, e o mérito refere-se a aspectos políticos, diferenciando de acordo com a forma de governo,

\footnotetext{
${ }^{8}$ Ou seja: $\quad \underline{\text { Homem A }}=\underline{\text { Benefício A }}$ ou $\underline{\text { Homem A }}=\underline{\text { Homem B }}$ Homem B Benefício B Benefício A Benefício B
}

Deste modo, se o homem A recebe um benefício A, então o homem B receberá um benefício B, do mesmo modo, em que, se o homem A tiver o mesmo mérito que o homem B, então, o benefício A terá que ser o mesmo do benefício B. 
seja ela a aristocrática, a oligárquica ou a democrática, de modo a ser determinada não de acordo com a igualdade entre as partes, mas sim proporcionalmente de modo geométrico.

Assim, por intermédio da justiça distributiva, uma pessoa recebe algo, que, certamente, será tanto maior quanto esta parte tenha maior relevo no todo. Por isto, na justiça distributiva se dá a uma pessoa tanto mais dos bens comuns quanto mais preponderância tenha essa pessoa na comunidade. Esta preponderância se determina na comunidade aristocrática pela virtude; na oligárquica, pelas riquezas; na democrática, pela liberdade, e em outras, de outra forma. (AQUINO, 1990).

Aquino salienta o fato de que as pessoas podem pleitear como sendo de sua propriedade qualquer bem que acaso necessitem em uma situação na qual houvesse risco iminente à sua vida. ${ }^{9}$ Tudo aquilo que contraria o direito natural é ilícito, sendo comuns todas as coisas. Deste modo, qualquer pessoa pode se apropriar de algo exterior.

Mas não se justifica o furto em estado de necessidade sem que haja a possibilidade de risco iminente. Destarte, para Aquino, somente se justifica um ato contrário à lei se o mesmo se fizer necessário à manutenção da vida. Se a necessidade for evidente e urgente, qualquer pessoa pode, licitamente, satisfazer sua necessidade com as coisas alheias.

Assim, percebe-se a continuação do conceito aristotélico de justiça distributiva no pensamento de Aquino. Todavia, esse introduz embrionariamente um elemento cristão na definição de justiça, influenciando posteriormente a modificação do conceito de justiça distributiva: a justificativa da possibilidade de se considerar a situação de pobreza de alguém que comete furto em relação à restituição do objeto furtado, trazendo ao conceito aristotélico de justiça, elementos cristãos, caridade com os pobres, perdão.

Em relação à transformação operada no significado de justiça distributiva, fazendo com que o sentido clássico aristotélico se alterasse, é importante também a contribuição de Adam Smith (1999), ancorado nos pensamentos de Hutcheson e Pufendorf, fazendo uma divisão entre direitos perfeitos e direitos imperfeitos. Sendo os direitos perfeitos relacionados à vida, integridade física,

\footnotetext{
${ }^{9}$ Quando um indivíduo está sob risco de inanição, ele pode apanhar frutas de uma árvore próxima ou beber água de um poço que encontre no seu caminho, independentemente de quem seja o dono da árvore ou do poço, e o alimento e a bebida de que ele necessita lhe pertencem, e não àquela pessoa que comumente tem a propriedade. (FLEISCHACKER, 2006, p. 43). Nesse caso, Aquino não considera o ato nem como um furto justificado, mas sim exercício legítimo do direito de propriedade.
} 
liberdade, propriedade, e os imperfeitos relacionados às ajudas caridosas que o homem recebe dos outros.

Os direitos perfeitos são vinculados à justiça comutativa de Aristóteles e os imperfeitos à justiça distributiva, relacionando-os a mérito e necessidade. Destarte, Smith reconhece que, em determinadas circunstâncias, "as pessoas têm um direito estrito à beneficência, que pode ser imposto coercitivamente". (FLEISCHACKER, 2006, p. 40-41). Além do fato de que sentir muito pelos outros e pouco por nós mesmos, restringir nossos afetos egoístas e cultivar os benevolentes, constitui a perfeição da natureza humana; e somente assim se pode produzir entre os homens a harmonia de sentimentos e paixões em que consiste toda a sua graça e propriedade. E assim como amar a nosso próximo do mesmo modo que amamos a nós mesmos constitui a principal regra do Cristianismo. (SMITH, 1999).

É importante destacar que ainda não há uma tradição, neste momento, em se atribuir à justiça distributiva a característica de se cuidar dos pobres, aliviando seu sofrimento, mas sim os deveres de pais para filhos, amigos para vizinhos, e de todos para com pessoas "de mérito".

Enfim, a justiça distributiva se aplica à distribuição dos bens, das honras e dos cargos na pólis. Sempre com vistas à igualdade, parte esta modalidade de justiça da premissa de que os homens são desiguais, merecendo, portanto, tratamento desigual. Ensina Giorgio Del Vecchio: "A justiça distributiva consiste, pois, em uma relação proporcional, que Aristóteles, não sem algum artifício, define como uma proporção geométrica”. (VECCHIO, 2006, p. 25).

O critério para o rateio está no mérito de cada indivíduo, de acordo com a complexidade, do esforço e dos sacrifícios de cada um. Pense-se numa grande obra. O sucesso de sua execução exige trabalhos diversos. É necessária a atuação de um engenheiro e de um arquiteto na elaboração dos esquemas e planejamento dos serviços. Trata-se, sem dúvida, do serviço mais complexo, sendo exigido dos profissionais conhecimentos técnicos específicos e cálculos que extrapolam o saber do homem médio.

Em contrapartida, em geral são outros os profissionais que darão cabo à realização da obra, seguindo as determinações daqueles que a planejaram. Na medida em que suas tarefas são distintas, havendo menor exigência de conhecimentos técnicos e sendo seus serviços menos complexos do ponto de vista intelectivo, ao final da obra, seus méritos não serão em mesma medida dos primeiros citados. Desta forma, a distribuição dos bens e das honrarias devidas serão proporcionais aos méritos de cada um no resultado dos trabalhos. 
Nessa esteira, ressalta Michel Villey (2005) que a justiça visará, por exemplo, a que que exista uma relação entre honraria e mérito.

Deste modo, a justiça distributiva aristotélica adota como parâmetro a distribuição de acordo com o mérito, adaptando-se à ideia de régua de lesbos, medida por intermédia da qual haverá uma distribuição desigual entre os benefícios e vantagens da sociedade.

\subsection{A justiça comutativa no pensamento aristotélico}

O termo justiça corretiva pode ser utilizado como sinônimo de justiça comutativa, que tem em si uma concepção de igualdade formal, equilíbrio linear, manifestando-se nas relações voluntárias e nas involuntárias. Trata-se de uma justiça das relações privadas, que, de fato, constitui uma espécie de igualdade. A injustiça nestas relações é uma espécie de desigualdade, mas não conforme à espécie de proporção mencionada acima, e sim conforme à proporção aritmética. (ARISTÓTELES, 1985).

A justiça comutativa (ou corretiva) é aquela que se aplica às relações privadas sinalagmáticas, cujo melhor exemplo é o contrato. Tem como fito a paridade, ou igualdade, nos resultados (ganhos e danos) da relação bilateral, fazendo uso da proporção aritmética. Veda, assim, que uma das partes obtenha vantagem num negócio ou numa ação com consequências para outrem.

Giorgio Del Vecchio (2006) ressalta que essa espécie de justiça tende a fazer que cada uma das duas partes que se encontre em uma relação venha a encontrar-se, em relação à outra, em uma condição de paridade, de modo que nenhuma tenha dado nem recebido a mais nem a menos. Deste modo, observa-se nesse conceito o ponto intermédio ou o meio entre o dano e a vantagem.

Há uma infinidade de exemplos que poderiam ser mencionados. Pense-se numa compra e venda envolvendo um veículo. Neste caso, impõe a justiça comutativa que o valor pago seja justo e correspondente à condição do bem objeto do negócio. Desta feita, há uma obrigação de equilíbrio e de justeza a ambas as partes. Uma delas está obrigada a entregar o veículo sem esconder defeitos (vale a lembrança do instituto dos vícios redibitórios). A outra está obrigada a pagar conforme o valor correspondente. Se uma das partes não cumpre sua obrigação, ocorre a disparidade e, portanto, a injustiça.

Impõe, assim, a justiça corretiva um ideal de equilíbrio entre as partes envolvidas em um negócio, impedindo que circunstâncias e outros fatores acarretem perdas para um lado e ganhos para outro lado. 
O Estagirita estende a aplicação desta justiça às ações involuntárias, desde que destas decorram dano a alguém. Mais uma vez, conforme destaca Giorgio Del Vecchio (2006), os termos vão se aplicando não somente às relações voluntárias ou contratuais, como também àquelas que Aristóteles denomina de involuntárias.

Destarte, a aplicação da justiça corretiva transcende o âmbito do direito civil-contratual, alcançando também a doutrina da responsabilidade civil e do direito penal, especialmente no que concerne à pena como retribuição, equiparada ao mal que do ato ilícito decorreu.

Com relação à aplicação em caso de ações involuntárias, no âmbito da responsabilidade civil, pode-se pensar, à título de exemplo, em alguém que, ainda que sem o elemento volitivo, destrói um bem alheio, como uma pessoa que esbarra em um objeto de vidro num estabelecimento comercial, levando-o ao chão. Em vista da justiça corretiva, estará esta pessoa obrigada a reparar o dano que causou ao dono do estabelecimento por seu ato, ainda que não doloso.

Michel Villey observa que muitos estudiosos perceberam na divisão da justiça em Aristóteles a futura dicotomia entre direito público e direito privado:

A divisão a que chegara o estudo de Aristóteles entre dois tipos de aplicação da justiça justiça distributiva e justiça comutativa -, decorrentes de métodos diferentes, era de grande fecundidade. Alguns autores veem nela a fonte da futura distinção entre direito público e direito privado. Caso se aceite que o estado e o direito público são competentes para realizar o primeiro trabalho, isto é, a distribuição dos patrimônios, pode-se constituir em seguida uma ciência autônoma para regular as comutações: seria o direito privado, que a ciência dos jurisconsultos teria desenvolvido a partir do princípio de igualdade simples, ou aritmética. De fato, os juristas romanos exploraram metodicamente este último princípio (teoria do enriquecimento sem causa; mutuum; preço justo; damnum injuria datum; condictiones sine causa). (VILLEY, 2005, p. 43).

Com efeito, o mesmo princípio que fundamenta a justiça comutativa é a fonte inspiradora de muitos institutos caros ao direito romano que permanecem em vigor ainda hoje, tais como o enriquecimento sem causa e o preço justo. No presente trabalho, defende-se que também pode-se incluir entre tais institutos a cláusula rebus sic stantibus, conforme a argumentação que se segue.

\section{CONTEÚDO E HISTÓRICO DA CLÁUSULA REBUS SIC STANTIBUS}

De acordo com Washington de Barros Monteiro (1987), sempre que o equilíbrio contratual for abalado, deve o contrato ser revisado pelo Estado-juiz, de acordo com circunstâncias, 
fundamentando-se nos princípios gerais do Direito e dos contratos, afastando-se, desse modo, a regra tradicional e imperativa, que imperou antes do advento necessário do Direito Civil constitucionalizado.

Rebus sic stantibus, que pode ser entendida como enquanto as coisas estão assim, é uma abreviação do trecho de uma glosa atribuída a Nerácio: “contractus qui habent tractum sucessivum et dependentiam de futuro rebus sic stantibus intelliguntur”. (OLIVEIRA, 1968). Recebeu outras denominações na evolução do pensamento jurídico moderno, como teoria da imprevisão, derivada do direito francês.

Trata-se de cláusula implícita nos contratos comutativos de obrigações sucessivas ou dependentes do futuro, cujo cumprimento fica condicionado à permanência do estado de fato contemporâneo da formação do vínculo. Se ocorre alteração do estado de fato, surge situação imprevisível quando da celebração do contrato, acarretando encargos excessivamente onerosos a uma das partes da relação. Tal fato ensejaria a revisão (reajuste) ou a resolução do contrato em juízo. Assim é a doutrina de Anísio José de Oliveira:

Há certos contratos que são celebrados num dado momento para serem cumpridos em
época diversa. São os contratos de execução diferida ou sucessiva. Não raro o cidadão X
celebra um contrato com o cidadão Y para ser cumprido in futurum. E entre o momento
da celebração e o em que deveria ser realizada a execução do contrato, surge um
acontecimento imprevisto tornando a prestação sumamente onerosa para o devedor. Este
contrato celebrado entre X e Y há de ser sempre, para servir-nos de exemplo, comutativo
(é aquele contato no qual as partes contratantes desde logo podem conhecer a extensão da
prestação e da contraprestação). Presume-se então que nos contratos comutativos a termo
ou de execução sucessiva haja uma cláusula implícita que vai resolvê-lo quando ocorrer
um acontecimento imprevisto, modificador da situação econômica objetiva. Esta cláusula
subentendida nestes contratos é que se denomina "cláusula rebus sic stantibus".
(OLIVEIRA, 1968, p. 24-25).

Conforme destaca Renato José de Moraes (2001), há dois sentidos para a cláusula rebus sic stantibus. O primeiro deles, mais amplo, considera que os vários atos jurídicos têm sua eficácia subordinada à permanência das características como estavam no momento de sua celebração. Diante disso, qualquer alteração nas características de um determinado momento é hábil a desestabilizar a permanência do ato jurídico.

Por sua vez, no segundo sentido, que trata a teoria imprevisão (mais estrito), entende a cláusula mediante a qual os contratos de execução periódica, podem ser resolvidos em decorrência de fato superveniente, imprevisível, que desequilibre o contrato. Assim, é necessária a ocorrência de uma mudança substancial que possa desestabilizar as cláusulas, sendo esse imprevisível para as 
partes. Em que pese serem legítimas ambas acepções, a segunda concepção (estrita) é a mais utilizada pela doutrina e pela jurisprudência.

Na esteira do ensinamento de Maria Helena Diniz (2009), são elencados, de forma sintética, os requisitos básicos para a admissão da teoria da imprevisão: I) o contrato comutativo e de execução continuada, e nunca de execução imediata; II) a alteração radical das condições econômicas; III) a ocorrência de onerosidade excessiva para uma das partes e de benefício exagerado para a outra, superior à normalidade contratual; IV) a imprevisibilidade e o caráter extraordinário dessa modificação.

Atualmente a teoria da imprevisão encontra amparo também no Direito Administrativo brasileiro, sendo aplicada aos contratos administrativos celebrados entre a Administração Pública e os particulares. A Lei n. ${ }^{\circ} 8.666 / 93{ }^{10}$ prevê como hipóteses de aplicação: o caso fortuito e a força maior, o fato do príncipe, o fato da administração e as interferências imprevistas.

\subsection{Histórico da cláusula rebus sic stantibus}

Como destacado, é acirrado o debate a respeito da origem da cláusula rebus sic stantibus ${ }^{11}$. Parece ser mais acertada a visão de que teve sua gênese no direito romano, embora neste não tenha encontrado aplicação, devido à sua ênfase no individualismo e na prevalência da pacta sunt servanda.

Desta forma, é no período medieval, com os glosadores e os mestres do direito canônico, que a rebus sic stantibus encontrou melhor amparo e acolhimento. Santo Tomás de Aquino dela tratou na Suma Teológica, fazendo referência ao romano Sêneca.

Ocorre que, com o ressurgimento do individualismo jurídico dos séculos XVIII e XIX, a cláusula sofreu severa resistência, sendo mais uma vez omitida dos ordenamentos jurídicos.

Com a Primeira Guerra Mundial (1914-1918) e suas desastrosas consequências, o mundo tornou a relativizar o individualismo contratual e a pacta sunt servanda. No Brasil, embora sem previsão expressa no Código Civil de 1916, a rebus sic stantibus passou a ser reconhecida em muitos casos pela jurisprudência. Todo esse contexto levou à sua positivação no Código Civil de 2002, in verbis:

\footnotetext{
${ }^{10}$ Em seus artigos 65, II, “d”, e 78, XIV, XV, XVI e XVII.

${ }^{11}$ Para um estudo aprofundado sobre o tema, vide a supracitada obra de Anísio José de Oliveira.
} 
Art. 317. Quando, por motivos imprevisíveis, sobrevier desproporção manifesta entre o valor da prestação devida e o do momento de sua execução, poderá o juiz corrigi-lo, a pedido da parte, de modo que assegure, quanto possível, o valor real da prestação. [...]

Art. 478. Nos contratos de execução continuada ou diferida, se a prestação de uma das partes se tornar excessivamente onerosa, com extrema vantagem para a outra, em virtude de acontecimentos extraordinários e imprevisíveis, poderá o devedor pedir a resolução do contrato. Os efeitos da sentença que a decretar retroagirão à data da citação. Art. 479. A resolução poderá ser evitada, oferecendo-se o réu a modificar equitativamente as condições do contrato.

Art. 480. Se no contrato as obrigações couberem a apenas uma das partes, poderá ela pleitear que a sua prestação seja reduzida, ou alterado o modo de executá-la, a fim de evitar a onerosidade excessiva. (BRASIL, 2019).

Ancorados nos dois significados, o estrito e o amplo, parece que o Código Civil, em sua redação, preferiu a segunda acepção, exigindo a desproporção manifesta em decorrência de motivos imprevisíveis, conforme se lê no caput do artigo 317, acima citado.

Apresentados os conceitos de justiça comutativa no pensamento aristotélico, como também, o conceito e as características da cláusula rebus sic stantibus, passa-se, na próxima seção, ao estudo comparativo entre, justamente, justiça comutativa e a referida cláusula.

\section{ANÁliSe COMPARATIVA ENTRE A JUSTIÇA COMUTATIVA E A CLÁUSULA REBUS SIC STANTIBUS}

Tendo exposto o essencial das doutrinas sobre a justiça comutativa e a cláusula rebus sic stantibus, passa-se, em conclusão, à problemática do trabalho, cuja finalidade é analisá-las comparativamente.

Segundo Harold Berman (2006), os conceitos aristotélicos foram essenciais à formação da teoria geral dos contratos, a partir do século XIV. Deste modo, foi depois de dois séculos, depois, ainda, da tradução da Metafísica e da Ética de Aristóteles, como também da aplicação da filosofia aristotélica à teologia por Tomás de Aquino, que os pós-glosadores - especialmente os juristas italianos do século XIV Bartolus e Baldus - foram capazes de continuar e elaborar mais do que uma síntese do Direito Romano dos Contratos (ou seja, uma teoria geral dos contratos).

Esses pós-glosadores realizaram a empreitada iniciando pelos conceitos aristotélicos de justiça distributiva e comutativa, substância e acidente, assim como as definições (também aristotélicas) de causa final, causa formal, causa material e causa eficiente. (BERMAN, 2006). 
Aristóteles propõe que as relações bilaterais - o que pode se aplicar às relações entre particulares e às que envolvam particulares e o Estado - sejam pautadas pelo ideal de paridade de perdas e ganhos decorrentes. Assim, atenta contra a justiça comutativa qualquer pacto ou contrato que implica em prejuízo e ônus excessivos a uma das partes. Sugere Aristóteles (1985) que o reajuste desse ser feito pela pessoa do juiz, a quem cabe restabelecer o equilíbrio do negócio.

O juiz então restabelece a igualdade, afirma Aristóteles (1985). As coisas se passam como se houvesse uma linha dividida em dois segmentos desiguais, subtraindo, o magistrado, a parte excedente à metade, e a acrescentando ao segmento menor. Caso haja uma divisão justa, as partes dirão que possuem aquilo que pertencem. "O igual é o meio termo entre a linha maior e a menor de acordo com a proporção aritmética.” (ARISTÓTELES, 1985, p. 98).

Claramente tal lição afronta a teoria da autonomia da vontade e a tradicional cláusula pacta sunt servanda, em vista de um ideal de justiça que deve ser proporcionado pelo Estado-Juiz. Não é equivocado afirmar que o princípio da socialidade, que inspirou a construção do Código Civil de 2002, já estava presente na obra do mestre grego há mais de dois mil anos.

Ora, o mesmo escopo que foi reproduzido alhures é o que justifica a existência implícita da cláusula rebus sic stantibus. O surgimento de um fato imprevisível e extraordinário após a ocorrência de um pacto não pode ser suportado em sua onerosidade por apenas uma das partes, enquanto a outra se beneficia. É imperioso que o negócio seja reajustado ou resolvido, seja por própria inciativa das partes, seja pela atuação jurisdicional.

Interessante a observação doutrinária de Maria Helena Diniz e a comparação com o texto aristotélico:

O princípio da autonomia da vontade não é onímodo, mas sofre limitações, oriundas do dirigismo contratual, que, ao invocar a supremacia do interesse público, ínsita no princípio da socialidade do direito, intervém na economia do contrato, aplicando normas de ordem pública e impondo a adoção de sua revisão judicial. Isso acontece quando a superveniência de casos extraordinários e imprevisíveis por ocasião da formação do contrato, que o tornam, de um lado, excessivamente oneroso para um dos contraentes, gerando a impossibilidade subjetiva de sua execução, e acarretam, de outro, lucro desarrazoado para a outras partes. Isso é assim porque impera o entendimento de que, se permitisse aos contratantes convencionar, a seu bel-prazer, o ato negocial, estipulando quaisquer cláusulas sem que o juiz pudesse intervir, mesmo quando se arruinasse uma das partes, a ordem jurídica não cumpriria o seu objetivo de assegurar a igualdade econômica, ou melhor, o equilíbrio econômico-financeiro do contrato. (DINIZ, 2009, p. 163). 
Resta evidenciado: a finalidade da ordem jurídica, e, portanto, de seu instituto da cláusula rebus sic stantibus, é garantir a igualdade, o equilíbrio econômico-financeiro da relação, em outras palavras, fazer cumprir a justiça comutativa aristotélica.

\section{CONSIDERAÇÕES FINAIS}

A obra de Aristóteles se destaca pela sua multidisciplinariedade, tendo tratado de um considerável número de saberes, em todos eles com considerações ainda hoje relevantes. Com o Direito não é diferente, destacando-se, neste âmbito, sua "Política" e a "Ética a Nicômaco".

O Estagirita foi um dos primeiros filósofos a se preocupar com o conceito de justiça, apresentando, no Livro V, da obra Ética a Nicômaco, um esquema de justiça, dividindo a justiça em espécies: justiça distributiva, justiça comutativa.

A justiça distributiva (que é controversa, de acordo com os parâmetros democráticos atuais) decorre do exercício da distribuição de honrarias, riqueza. Essa não se baseia na igualdade aritmética, mas sim numa igualdade de proporções entre pessoas e bens. Os iguais recebem, de acordo com essa espécie, partes iguais, enquanto os desiguais recebem partes desiguais.

Por sua vez, a justiça comutativa, também denominada justiça comutativa, é aquela por intermédio da qual há uma aplicação de igualdade aritmética simples em relação aos indivíduos e bens.

A cláusula rebus sic stantibus fundamenta a revisão dos contratos, restabelecendo o equilíbrio contratual, quando esse for abalado, em decorrência de circunstâncias imprevisíveis.

A doutrina não sabe precisar sua origem. Encontram-se elementos seus no direito romano. Entretanto, foi somente no medievo que passou a receber um tratamento doutrinário mais elaborado. Com o ressurgimento do individualismo, perdeu forças, sendo quase esquecida, retornando com o Estado Democrático de Direito, preocupado com o bem-estar social, sendo, inclusive, positivada no ordenamento jurídico brasileiro.

A doutrina observa dois sentidos para a cláusula: $i$ ) um sentido amplo e ii) um sentido estrito. De acordo com o sentido amplo, é necessário que todas as características do contrato permaneçam como estavam no momento de sua celebração. Por sua vez, conforme consta na axiologia do sentido estrito, haverá aplicação da cláusula, devendo ser revisado o contrato, 
mediante a ocorrência de fato superveniente, imprevisível entre as partes, hábil a desequilibrar a relação contratual.

Voltando à problemática do estudo, estampada na introdução, sugerindo a existência de estrita relação principiológica entre a doutrina de Aristóteles e a cláusula rebus sic stantibus, prevista, inclusive, no ordenamento jurídico nacional, percebe-se, após estudo da obra aristotélica, sua influência na estruturação da referida cláusula.

Pelo exposto, a despeito do problema envolvendo a origem da cláusula rebus sic stantibus, resta evidenciado que tal instituto segue o princípio de justiça comutativa desenvolvido por Aristóteles no seu tratado de ética. Forçoso é afirmar que, diante disso, há elementos plausíveis da cláusula no pensamento aristotélico, o que comprova a hipótese do estudo.

Assim, quanto mais se busca na Filosofia elementos para a compreensão dos institutos jurídicos, mais se percebe a estrita relação existente entre Filosofia e Direito, uma relação, por consequência, de criador e criatura, tão importante para o desenvolvimento do pensamento jurídico ocidental.

\section{REFERÊNCIAS}

AQUINO, Tomás de. Suma Teológica. 4. ed. Campinas: Ecclesiae, 2016, V. 3.

ARISTÓTELES. A política. 3. ed. São Paulo: Martins Fontes, 2006.

ARISTÓTELES. Ética a Nicômaco. Brasília: Universidade de Brasília, 1985.

BARNES, Jonathan (Org.). The cambridge companion to Aristotle. Cambridge: Cambridge University, 1995.

BERMAN, Harold J. Direito e revolução: a formação da tradição jurídica ocidental. São Leopoldo: UNISINOS. 2006.

BRASIL. Código Civil de 2002. Promulgado em 10 de janeiro de 2002. Disponível em: http://www.planalto.gov.br/ccivil_03/leis/2002/110406.htm. Acesso em: 02 nov. 2018.

DINIZ, Maria Helena. Curso de direito civil brasileiro: teoria das obrigações contratuais e extracontratuais. 25. ed. São Paulo: Saraiva, 2009.

FLEISCHACKER, Samuel. Uma breve história da justiça distributiva. São Paulo: Martins Fontes, 2006. 
HUTCHINSON, Douglas S. Ethics. In: BARNES, Jonathan (Org.). The cambridge companion to Aristotle. Cambridge: Cambridge University, 1995, p. 195-232.

MONTEIRO, Washington de Barros. Curso de direito civil: direito das obrigações. São Paulo: Saraiva, 1987.

MORAES, Renato José de. Cláusula rebus sic stantibus. São Paulo: Saraiva, 2001.

OLIVEIRA, Anísio José de. A cláusula rebus sic stantibus através dos tempos. Belo Horizonte. Ibérica, 1968.

SMITH, Adam. Teoria dos sentimentos morais. São Paulo: Martins Fontes, 1999.

STRAUSS, Leo et al. História da filosofia política. Rio de Janeiro: Forense, 2013.

VECCHIO, Giorgio Del. História da filosofia do direito. Belo Horizonte: Líder, 2006.

VILLEY, Michel. A formação do pensamento jurídico moderno. São Paulo: Martins Fontes, 2005.

\title{
THE REBUS SIC STANTIBUS CLAUSE IN THE LIGHT OF ARISTOTELIC COMMUTATIVE JUSTICE
}

\begin{abstract}
The rebus sic stantibus clause, affirmed by the Brazilian legal system, has a strict principled relationship with commutative justice, elaborated by Aristotle (384 BC-322 BC), especially regarding teleology. The theory of unpredictability aims to promote fairness in contractual relations when circumstances change in view of the balance of benefits and losses of the parties. The hypothetical-deductive study, supported by expositors of Aristotelian jusphilosophical doctrine and the history and application of the rebus sic stantibus clause, aims to analyze the subjects, in their philosophical assumptions and their historical scope, in order to find convergences and influences. It is concluded by the manifest relation of the basic elements of the institutes, which has the same purpose, although it is not possible to fully affirm the historical link of influence of the Aristotelian doctrine in the emergence of the clause.
\end{abstract}

Keywords: Commutative justice. Distributive justice. Rebus sic stantibus clause. Brazil. 